\title{
Ativismo e extrema-direita no meio militar: tensões e discursos que antecedem o bolsonarismo (1984-1998)
}

Eduardo Heleno de Jesus Santos

Resumo: Embora a redemocratização tenha resultado em um novo status quo, subordinando as Forças Armadas ao poder civil, certas continuidades do discurso autoritário e anticomunista do regime militar serão observadas nas décadas de 1980 e 1990, expressas em um ativismo militar de extrema-direita, conformado por oficiais da reserva. As ações destes grupos de pressão se inserem na dinâmica das relações civis e militares do período, e seus discursos são marcados pelo ressentimento em relação aos civis, pelas soluções autoritárias e pelo anticomunismo. Ao final serão apresentadas convergências entre esses discursos e o fenômeno bolsonarista.

Abstract: Although Brazil's democratization in the 1980's resulted in a new status quo for the Armed Forces, submitting them to civilian authority, some essential aspects of the authoritarian and anticommunist discourse that had prevailed during the military regime continued to be observed in the 1980s and 1990s. This rhetoric was marked by resentment against civilians, authoritarian proposals and anti-communism, and found its expression in a far-right military activism undertaken by retired officers in that period. Actions by these activist pressure groups were part of the civilian-military relationship dynamics. Towards its conclusion, this article presents the existing convergences between this post-democratic transition discourse and the contemporary pro-Bolsonaro phenomenon. 
O avanço da extrema-direita em nível global, e a eleição de Jair Bolsonaro em particular, trouxe a reboque um novo desafio para as Ciências Sociais brasileiras: buscar entender o retorno da participação dos militares na política e compreender como se insere o populismo de direita no país. Nesse sentido, será a mobilização dos militares da ativa e da reserva em torno dos ideais anticomunistas, como os expressos por Bolsonaro, um fenômeno recente? Quais seriam as aproximações e afastamentos desse ativismo militar com a trajetória política de Bolsonaro? Mostraremos ao longo desse trabalho que, embora a redemocratização tenha resultado em um novo status quo para as Forças Armadas brasileiras, certas continuidades do discurso autoritário e anticomunista do regime militar serão observadas na redemocratização expressas em um ativismo militar de extrema-direita, conformado por oficiais da reserva, e que será mais tarde utilizado por Bolsonaro em suas prédicas. Bolsonaro, por sua vez, desde o início da década de 1990, será um dos articuladores de outro ativismo militar, relacionado à melhoria salarial, e que aglutinará as baixas patentes.

No campo do estudo das Relações Civis e Militares no Brasil, há uma densa bibliografia que aborda os mais distintos aspectos da redemocratização. Como não é o objetivo deste artigo um estado-da-arte desse campo da Ciência Política, permitirei, por simplificação, a referência a alguns autores que dialogam com essa temática. Jorge Zaverucha contribui com uma leitura crítica sobre a manutenção de prerrogativas dos militares na transição e entre o governo Collor e o governo FHC (2000). Samuel Alves Soares (2006) analisa a relação entre a autonomia política dos militares e a função constituição das Forças Armadas. Gláucio Soares, Celso Castro e Maria Celina D’Araujo (2000; 2001), em diferentes publicações, nos trazem a memória dos oficiais da ativa que ocuparam importantes cargos na redemocratização. No que tange à interface das relações civis e militares brasileiras com as atividades de lobby e pressão, (Costa, 1998) analisou o surgimento da assessoria parlamentar do Exército nas atividades de lobby na Constituinte. Em que pese a quantidade e a densidade de obras feitas tanto por brasileiros quanto por brasilianistas, há uma lacuna diante de um fenômeno pouco conhecido que esteve presente desde a redemocratização: o ativismo militar dos oficiais da reserva. As poucas referências podemos encontrar em Dreifuss (1989) e Zaverucha (2000). Na literatura brasileira sobre grupos de pressão, há também lacunas sobre a participação dos militares na década de 1990. Embora Costa (1998) tenha abordado o lobby do Exército na Constituinte, faltava entender este tipo de ativismo político surgido entre os oficiais da reserva.

Este ativismo traduziu-se pela criação de grupos de pressão política. Gianfranco Pasquino (2004, p.564) define um grupo de pressão política como a "organização formal e pela ação direcionada a influenciar as decisões tomadas pelo poder político". Uma das suas atividades é a pressão. Para Pasquino, a pressão pode ser exercida por meio de sanções ou ameaças. Murillo de Aragão (1994, p.37) por sua vez entende que esta não é uma regra absoluta, afinal pressionar o poder público nem sempre implica constrangimento - há necessidade de convencimento, esclarecimento, 
informação e doutrinamento. Neste sentido, converge com Jean Meynaud (1966), para quem os métodos de pressão abarcariam, além das ameaças, a tentativa de persuasão, a cooptação pelo dinheiro, a sabotagem da ação governamental e a ação direta, com manifestações e greves.

Os grupos desta pesquisa podem ser divididos em duas grandes tendências. Falaremos primeiro sobre os grupos liderados majoritariamente por generais e coronéis da reserva, muitos com participação nos órgãos de segurança e informações do regime militar. As principais demandas destes grupos se relacionavam com o retorno ao status quo ante das Forças Armadas e a não punição dos militares envolvidos em crimes de lesa-humanidade. A prédica destas entidades se caracterizava pelo ressentimento em relação aos civis, por um acentuado anticomunismo e pela defesa de intervenção militar em casos de crise política.

Como grupos de pressão política, tentaram sensibilizar a sociedade por meio de artigos em mídia própria (jornais, revistas, livros, programas de rádio e sites) ou em espaços da grande imprensa. Em especial no Brasil, buscaram, em diferentes períodos, mobilizar candidaturas para uma bancada militar, sem sucesso.

Os oficiais destes grupos têm suas carreiras marcadas pelo pertencimento à comunidade de informações e segurança, e uma visão de mundo ancorada na doutrina de Segurança Nacional da Escola Superior de Guerra, anticomunista e voltada para o inimigo interno (Santos, 2015).

Como ponto inicial, devemos deixar claro que estes grupos não representam a totalidade das correntes existentes dentro das Forças Armadas e tampouco na reserva. Esses grupos estudados se vinculam majoritariamente ao Exército, devido ao histórico de intervenção na política brasileira.

A segunda tendência, com menor influência que a primeira, pode ser vista em associações de militares e pensionistas, que passam a ser criadas a partir da Constituição de 1988. Embora em algumas ocasiões elas se comportem ora como grupo de interesse, ora grupo de pressão política, para delimitá-las em relação aos grupos antes apresentados, tomaremos como referencial teórico a simplificação exposta por Jean Meynaud (apud Aragão, 1994, p.46), segundo a qual podemos dividir os grupos de pressão em duas categorias básicas: organizações patronais e agrupamentos de vocação ideológica. Como nos interessa mais a questão política do que a econômica, manteremos a designação grupo de pressão política para os agrupamentos de vocação ideológica e utilizaremos a expressão grupos sindicais, associações, em relação ao segundo grupo.

Um dos atores importantes nesse ativismo sindical dos militares será Jair Bolsonaro, deputado federal. Sua base eleitoral será a de militares de baixa patente. Ele se tornou conhecido na década de 1990 por suas declarações polêmicas em defesa do regime militar e de soluções golpistas. A defesa do regime militar é ainda hoje uma das bases do Bolsonarismo. Entendemos esse fenômeno político como a ascensão de uma extrema-direita, na década de 2010, ancorada em algumas temáticas específicas, como o anticomunismo, o reacionarismo, o ressentimento em relação aos civis 
e a defesa do regime militar, e em algumas práticas, como a militarização da máquina pública, o tensionamento das instituições e a manipulação midiática e das redes sociais.

\section{Metodologia e Referencial teórico ${ }^{1}$}

Os resultados encontrados aqui envolvem uma pesquisa que começou no mestrado, com o estudo exploratório dos grupos pressão política formado por militares da reserva no Brasil (Santos, 2009), e seguiu no doutorado, em um estudo comparativo sobre a dinâmica destes grupos em outros países do Mercosul (Santos, 2015). Ao longo desses anos foram catalogados os grupos criados a partir da redemocratização desses países. Para entender sua formação, seus objetivos e interesses políticos, foram realizadas entrevistas em profundidade com alguns de seus integrantes, sobretudo aqueles que ocupavam a direção dos grupos. Os documentos destes grupos, tais como materiais de divulgação, livretos, manifestos, programas de rádio, sites e declarações à imprensa em geral foram analisados a partir do contexto político em geral, e o das Forças Armadas, em particular.

Alguns grupos se nuclearam em tabloides militares, como o Letras em Marcha e o Ombro a Ombro. Esses dois jornais são importantes fontes das atividades dos grupos de pressão política, pois serviam para que seus integrantes divulgassem manifestos e artigos de opinião. A pesquisa contou com a leitura das edições de Ombro a Ombro de 1988, ano de sua criação, a 2004, ano de sua extinção. Em relação ao Letras em Marcha, o período analisado começa em 1971 e vai até 1999, ano da última edição.

Para entender o impacto destes grupos de pressão política nas relações civis e militares, foram analisadas matérias jornalísticas publicadas nos jornais de grande circulação, declarações dos clubes militares, citações em biografias de presidentes e ex-ministros da defesa. A pesquisa também teve acesso a documentos desclassificados da Secretaria de Assuntos Estratégicos (SAE) da Presidência da República e do Serviço Nacional de Informações (SNI). A citação desses grupos de pressão política nos relatórios do SNI e da SAE, a partir de recortes da imprensa, demonstra a repercussão de suas ações de pressão política. No que tange às associações de militares e a atuação de Bolsonaro, que se inserem em uma investigação mais recente, a pesquisa levou em conta os documentos nas páginas oficiais das entidades, os discursos de Bolsonaro nos diários da Câmara dos Deputados, a repercussão na imprensa de suas ações nos principais jornais do país e as citações nos informes do SNI e da SAE.

\footnotetext{
${ }^{1}$ Este trabalho se origina da dissertação e da tese defendidos pelo autor em 2009 e 2015 , respectivamente, e de acréscimos e revisões efetuados nos últimos anos.
} 


\section{A redemocratização - entre o esquecimento e a memória}

No Brasil, desde a redemocratização militares da reserva e civis passaram a organizar grupos de pressão política para mobilizar a opinião pública contra os governos constituídos. Diante da possibilidade de uma reversão da lei de Anistia ou mesmo de julgamentos como ocorridos na Argentina, esses grupos vão se mobilizar contra o avanço das esquerdas, para defender as ações ocorridas no regime militar e para criticar a nova ordem democrática.

Em sua maioria, não se trata de entidades clandestinas; a maior parte dos grupos encontrados foi registrada em cartório. Nos quatro países que formaram inicialmente o Mercosul, foram encontrados 33 grupos de pressão política formados por militares da reserva com atuação entre 1984 e 2014. A maior parte, 22 deles, foi criada no Brasil. Para este artigo, apresentaremos os mais proeminentes entre os grupos brasileiros.

A constituição de grupos de pressão política por militares acaba sendo uma tendência na redemocratização desses países, em especial no Brasil e na Argentina. Em um estudo sobre a formação de grupos similares nos Estados Unidos, Gwyn Harries-Jenkins aponta que quando o governo deixa de ser o garantidor dos militares, e quando há perda de prestígio social, há uma tendência dos militares se organizarem em grupos de pressão política (Harries-Jenkins, 1997, p.68 apud Bartle, Heinecken, 2006, p.2). Essa perda do prestígio está relacionada aqui no Brasil com o status quo advindo com a Nova República. Neste novo arranjo, embora as Forças Armadas tivessem influência, em especial no governo Sarney, houve uma gradativa saída dos militares da arena política, com críticas ao regime militar e a desvalorização de certos aspectos da cultura militar. Diferente da República de 1946, na qual os militares tiveram papel político atuante, a Nova República valorizou os civis. O novo status quo impõe certo isolamento político dos militares da competição político-partidária (Santos, 2015). Além disso, a redemocratização permitia a participação dos partidos de esquerda e movimentos sociais críticos aos militares.

Podemos dizer que o discurso de seus integrantes se situa majoritariamente no campo da extrema-direita. Alguns elementos convergem para essa definição: uma visão da democracia na qual apenas a direita conservadora é levada em consideração; um forte anticomunismo - segundo o qual qualquer ligação com o campo político à esquerda é vista com desconfiança -; a defesa dos valores conservadores; a defesa do regime militar; a defesa da intervenção militar e, por fim, um nacionalismo exacerbado.

Podemos ver a genealogia desses grupos em duas publicações que serviam como jornais para os militares da ativa e da reserva, o Letras em Marcha e o Ombro a Ombro. Ambas publicações tinham entre seus integrantes oficiais que fizeram curso na Escola Superior de Guerra, que trabalharam nos serviços ligados à comunidade de informações e inteligência, ou que fizeram parte das turmas formadas pelo Centro de Comunicações do Exército. Sabemos que a Escola Superior de Guerra 
exerceu papel preponderante na disseminação da Teoria da Guerra Revolucionária, que balizou não somente o argumento de controle político militar sobre a segurança interna como também na criação do arcabouço jurídico que funda e mantém o regime militar (Chirio, 2012; Kubik, 2019; Martins Filho, 2008; Santos, 2019).

Participavam do Letras em Marcha oficiais alunos do curso de Comunicação Social do Exército, militares já na reserva - como os oficiais generais Aurélio de Lyra Tavares (ex-integrante da Junta Militar), Carlos Alberto Fontoura (ex-chefe do Serviço Nacional de Informações no governo Médici), João Paulo Moreira Burnier (notório conspirador da Força Aérea), Carlos de Meira Mattos (um dos formuladores da geopolítica brasileira na Escola Superior de Guerra) e Sebastião Ramos de Castro (ex-chefe da Agência Central do SNI e ex-comandante do II Exército); os coronéis Antônio Erasmo Dias (ex-secretário de Segurança Pública de São Paulo), Hélio Ibiapina de Lima (um dos coronéis do IPM), Renato Brilhante Ustra (irmão do também coronel Ustra, acusado de ser torturador no DOI-Codi), entre outros. Com o apoio de empresas como Sharp e o Banco Nacional, o Letras em Marcha era distribuído nos quartéis junto com o Noticiário do Exército.

Este mensário militar se tornará panfletário nos meses que antecedem à eleição indireta para presidente da República, em 1984. O Centro de Inteligência do Exército vai aproveitar a capilaridade do Letras em Marcha, cuja distribuição chegava à tropa, para desestabilizar a campanha de Tancredo Neves, então candidato da oposição.

A “Operação dos Bruxos”, organizada pelo general Iris Lustosa, com o apoio dos generais José Luiz Coelho Netto, chefe de gabinete e Walter Pires, comandante do Exército, tinha o objetivo de deslegitimar a candidatura de Tancredo Neves junto aos militares (Jornal do Brasil, 1984, p.3). Em diferentes artigos publicados no Letras em Marcha, Neves era comparado tanto a Raul Alfonsín quanto a Alexander Kerensky. A referência servia para motivar a percepção de ameaça em relação ao processo de transição, que poderia redundar em revanchismo e até mesmo em revolução. Enquanto o jornal publicava os artigos, os agentes do CIE se infiltravam com bandeiras vermelhas nos comícios, colavam cartazes e pichavam as ruas de Brasília com o símbolo do Partido Comunista e a expressão "chegaremos lá". Na visão de René Dreifuss, o objetivo do CIE era menos apoiar o candidato governista Paulo Maluf e mais criar um ambiente para um golpe branco, e com isso perpetuar por mais alguns anos o regime militar (Filho et al, 1987; Dreifuss,1989, p.86).

O receio em relação ao "revanchismo" era evidente. O informe 1718 do Centro de Inteligência do Exército, de 31 de dezembro de 1984, avaliava que “as organizações clandestinas já estariam preparando uma relação de mortos e desaparecidos da 'época da repressão', bem como uma lista dos principais responsáveis, civis e militares", e que haveria, após a vitória de Tancredo Neves, uma ampla divulgação nos órgãos de comunicação social. O dossiê ACE047091 da Agência Central do 
SNI, de 04 de janeiro de 1985, amparado no noticiário da imprensa, indicava a dificuldade de Tancredo Neves em conter o revanchismo de esquerda.

O discurso da chamada "Ameaça Vermelha", tão caro a estes militares, não tem início na redemocratização ou mesmo no regime militar. Nos quartéis, sua disseminação situa-se na tumultuada década de 1930. O Exército, convulsionado pela Revolução de 1930, enfrentará a guerra civil de São Paulo de 1932 e uma série de quarteladas, motins e sublevações até 1938. Entre estes, o mais famoso será conhecido como a Intentona Comunista, quando militares dos quartéis de Natal, Recife e do Rio de Janeiro, tomam as unidades e tentam organizar um movimento revolucionário. $\mathrm{O}$ episódio se torna mais conhecido devido ao culto anticomunista criado pelo governo Vargas e mantido por décadas no Exército (Santos, Alves, 2014, p.138; Motta, 2002, p.203).

O receio de revanchismo entre os militares brasileiros não era recente - havia sido uma das preocupações que baseou o processo de distensão realizado pelo general Geisel, e já nos últimos anos do governo do general Figueiredo, ganhou mais força a partir do que acontecia na Argentina. Derrotados na Guerra das Malvinas, os generais argentinos viram o governo entrar em colapso, e não conseguiram fazer a transição para os civis. Diferentemente da transição argentina, o processo de redemocratização brasileiro foi marcado pela tutela. Com a morte de Tancredo Neves, que era o líder da oposição, assume a presidência o vice, José Sarney, que por muito tempo fora um dos nomes do partido governista, Arena, e que havia se incompatibilizado com o governo em 1984, ao fundar a Frente Liberal. Sem ter o respaldo de uma eleição direta, o vice que virou presidente não pode efetuar mudanças para um modelo de subordinação dos militares em que houvesse a punição dos crimes ocorridos no regime militar. Além disso, o consenso entre as elites nos Três Poderes impedia uma ampliação da agenda de revisão do passado como fora feito na Argentina.

No âmbito dos grupos de pressão política formados por militares da reserva, surge em 1985 a Associação da Defesa da Democracia (ABDD), composta por 21 militares da ativa, dez reserva e 14 civis. Os militares da ABDD tinham profunda ligação com o Centro de Inteligência do Exército, entre eles o coronel Audir Maciel, ex-comandante do DOI-CODI, o coronel Agnaldo Del Nero Augusto, chefe do Departamento de Subversão, o coronel José Augusto da Silveira Andrade Netto, chefe do Departamento de Propaganda e Contrainformação. A ABDD, mais tarde renomeada União Brasileira de Defesa da Democracia (UNDD), visava influir no trabalho da Comissão de Sistematização da Assembleia Constituinte (Dreifuss, 1989, p.173; Santos, 2015, p.79).

De acordo com Zaverucha, a primeira minuta da Comissão de Sistematização indicava que as Forças Armadas perderiam o seu papel de guardiões da lei e da ordem, o que causou a reação do então ministro do Exército, general Leônidas Pires Gonçalves, que chegou a declarar que "uma minoria ativa e vigilante vinha conduzindo os trabalhos". Ainda para Zaverucha, a reação do ministro teria ensejado "uma reorganização conservadora no Congresso". Neste momento, foi 
Santos, Eduardo Heleno de Jesus. Ativismo e extrema-direita no meio militar: tensões e discursos que antecedem o bolsonarismo (1984-1998).

criado o Centrão, um bloco que à época contava com 300 membros e que garantia ao governo a maioria da Constituinte (Zaverucha, 1994, p.186). Não há documentos que apontem a efetividade da UNDD como grupo de pressão para influenciar a Constituinte. No entanto, como aponta Dreifuss (1989, p. 174), a UNDD pode ser vista como parte de um esforço mais amplo da extrema-direita para desestabilizar o governo. A UNDD passou a cooptar setores empresariais e tinha como "aríete" o ex-presidente João Figueiredo. Nesse período, a participação do general em eventos serviu para aumentar a campanha contra o governo Sarney e de intimidação aos esquerdistas e aos liberais (idem).

Em entrevista dada ao jornal Ombro a Ombro em março (1989, p.2), o presidente da UNDD, professor Jorge Boaventura, docente da Escola Superior de Guerra, descrevia a União como uma instituição de caráter cívico militar, "fundada na tentativa de oferecer ponderações válidas à maré montante de esquerdização que, na conformidade da estratégia de Antonio Gramsci, que está sendo implementada entre nós pelos realizadores da revolução socializante (...)". A apropriação das ideias de Antônio Gramsci pela extrema-direita, entre elas o conceito de hegemonia, presente no discurso do presidente da UNDD e em outros grupos de militares da reserva, está relacionada à releitura de Gramsci realizada pelo teórico francês Alain de Benoist ainda na década de 1960, e que mais tarde seria uma das bases ideológicas da nova direita francesa. Aqui no Brasil, ganharia repercussão entre os militares do serviço de informações.

O alarmismo em relação ao avanço das esquerdas era mantido também entre os militares de países vizinhos. Na 17ª Conferência de Exércitos Americanos, realizada em Mar del Plata em 1987, foram assinados acordos secretos que poderiam dar azo à intervenção militar em caso de ameaça das esquerdas. O general Paulo Neves de Aquino, representante brasileiro, apresentou o documento oficial do Exército brasileiro, denominado Síntese da Situação da Subversão no Brasil. O documento alertava que $30 \%$ dos parlamentares que redigiam a nova Constituição brasileira eram militantes ou simpatizantes de organizações subversivas. Na mesma conferência, outro informe indicava que o PT, o PMDB e o PDT eram os partidos que sofriam "infiltração da subversão" (Câmara dos Deputados, 1988, p.3419).

Ao olhar detidamente a transcrição este documento no Diário da Câmara dos Deputados, nos impressiona como o discurso de integrantes do atual governo Bolsonaro, baseado no anticomunismo e, no antipetismo, converge com a verborragia conspiratória apresentada no final da guerra fria. O clima durante os últimos anos do governo Sarney era pautado pela possibilidade de golpe e de retorno dos militares ao poder. Se havia revanchismo, também podemos dizer que havia a percepção de que uma mudança profunda poderia afetar o sistema de privilégios, status e poder, mesmo em pequena escala, do qual muitos militares gozavam. A participação de militares na administração federal, em empresas de capital misto e na negociação com empresas privadas 
representa aqui as condições objetivas, enquanto a cruzada de extrema-direita lhe empresta a roupagem subjetiva.

Dentro desta visão, o general de brigada Sérgio Augusto de Avellar Coutinho, então chefe do Centro de Informações do Exército, alertava em 1989, em documento confidencial para o altocomando, o suposto surgimento de uma nova esquerda inspirada e influenciada por Gramsci (Godoy, 2021, p.57). Para Coutinho, a ameaça comunista do passado, representada por militantes marxistas, passa dar lugar a uma esquerda mais sutil e cuja revolução se daria por etapas, dentre elas o "intermezzo democrático". ${ }^{2} \mathrm{O}$ alerta dado por Coutinho em um órgão oficial de informação se somaria às campanhas feitas pelos jornais Letras em Marcha contrária ao avanço dos partidos de esquerda, em especial o Partido dos Trabalhadores, nas eleições de 1989 (Santos, 2009, p.92).

Ainda como reação ao chamado avanço das esquerdas, em 1988, havia sido criado o Grupo Independente 31 de março, com alguns oficiais que participavam do Letras em Marcha e da UNDD. Imersos na logica anticomunista, o objetivo do grupo era uma "luta sem trégua contra os comunistas, os 'progressistas' e contra a corrupção, como também uma possível colaboração ao melhor candidato à presidência da República". E um dos itens do seu plano estratégico, como mostra o dossiê da Agência Central do SNI, ACE 72519, de 1989, era "manter as Forças Armadas fora da campanha, mas informadas acerca da evolução dos acontecimentos". Entre seus integrantes, estava o brigadeiro da reserva Coqueiro; o general Sebastião Ramos de Castro, oficial do SNI no governo Médici; o coronel da reserva Gustavo Eugênio de Oliveira Borges, insurgente na revolta de Aragarças, entre outros. O 31 de Março enviava relatórios de conjuntura para a mala direta, que chegou a ter 1260 destinatários e artigos para jornais (Santos, 2009).

Mas antes de avançarmos, vale aqui uma referência, mesmo que primária, a um outro tipo de ativismo militar, que ainda merece uma série de investigações.

\section{O associativismo militar em prol de melhorias salariais}

Paralelo ao constante alarmismo em relação à esquerda, um dos pontos mais discutidos entre os militares da ativa e da reserva ao final dos anos 80 e início dos anos 1990 foi a questão salarial. Desde 1989, surgiam em todo Brasil as Associações de Servidores Militares da Reserva Remunerada, Reformados e Pensionistas das Forças Armadas e Auxiliares (ASMIR), que serão reunidas na Federação de Associação de Militares da Reserva (FAMIR).

Durante a década de 1990, Jair Bolsonaro não era influente para os grupos de pressão política constituídos por oficiais de alta patente, embora fosse uma liderança das associações de pensionistas,

\footnotetext{
${ }^{2}$ A partir da década de 2000, com a publicação do livro pela editora Ombro a Ombro, Coutinho se torna uma referência teórica para a extrema-direita militar.
} 
Santos, Eduardo Heleno de Jesus. Ativismo e extrema-direita no meio militar: tensões e discursos que antecedem o bolsonarismo (1984-1998).

conformadas pelas patentes mais baixas. Mostraremos os motivos desse afastamento e os pontos de aproximação.

Diferentemente dos grupos de pressão antes apresentados, que questionam e pressionam por uma mudança política, essas associações terão como assuntos principais os vencimentos, a pensão militar, o acesso à saúde dos militares. Para as pensionistas, que recebiam apenas um terço dos salários dos maridos, a adequação das pensões à integralidade garantida pela Constituição era uma medida de primeira necessidade. Deve-se levar em conta que não é permitido no Brasil o direito de greve para os militares das Forças Armadas. Com isso, as formas de pressão dessas entidades estarão voltadas ao convencimento de seus associados a respeito de seus direitos e a convocação de cônjuges de militares para protestos por salários.

Estas associações são dirigidas por oficiais de baixa patente e sargentos, contam com a presença de militares das três Forças, da Polícia e dos Bombeiros, e surgem diante das mudanças trazidas com a Constituição de 1988. Outras marcáveis diferenças entre o ativismo das associações de militares e dos oficiais veteranos do regime militar são os objetivos e o posicionamento políticoideológico. As associações de militares seriam parte dos grupos de pressão patronais, voltadas à questão salarial, econômica; e os grupos anticomunistas de oficiais da reserva estariam enquadrados na definição dos grupos de pressão política relacionado às pautas ideológicas como, por exemplo, a memória do regime militar, a questão da anistia, a participação política dos militares, a condução política do governo, a valorização do status social do militar.

Jair Bolsonaro, então vereador no Rio de Janeiro, atuará como vice-presidente da FAMIR. Bolsonaro irá organizar reuniões e palestras com esposas de militares para sensibilizar o seu eleitorado e pressionar as lideranças militares e o governo. Nos primeiros anos, essas atividades serão vistas com desconfiança pelos comandantes militares. Em 1989, o relatório do general Sérgio Avellar Coutinho critica a postura do então vereador Bolsonaro de enviar panfletos "nos quais procura enaltecer sua atuação política e, invariavelmente, abordar o assunto isonomia salarial". Reclama o general das declarações descabidas e inoportunas sobres os chefes, realizadas pelo então vereador, por semear o clima de discórdia, incompreensão e descrédito perante o público interno, por usar a pauta salarial para projetar seus interesses pessoais, entre outros aspectos. Em outro relatório, de setembro de 1989, o general demonstra preocupação com um suposto "sindicalismo fardado" alardeado pela imprensa e seus efeitos na corporação (CIE, 1989-a, p.6; CIE,1989-b, p.8; Godoy, 2019). Em fevereiro de 1991, o agora deputado federal Jair Bolsonaro chamará mais ainda a atenção de seus antigos superiores hierárquicos. No âmbito da Câmara dos Deputados, vemos o discurso de um Bolsonaro ainda crítico aos chefes militares.

Em abril de 1991, ele denuncia o general Jonas de Morais Correia Neto por este ter ordenado a prisão do segundo-tenente Antônio de Souza Garcia, presidente da FAMIR, por criticar 
publicamente a política de salários dos militares (Câmara dos Deputados, 1991-a, p.4408). Em setembro, por ordem do general Alberto dos Santos Lima Fajardo, do Comando de Operações Terrestres, Bolsonaro será impedido de entrar nos quartéis para fazer campanha (Câmara dos Deputados, 1991-b, p.17974) Em Brasília, segundo o próprio Bolsonaro, em discurso no plenário da Câmara, a ordem da cúpula militar era punir os militares cujas esposas fossem vistas em reuniões ou passeatas organizadas por ele (Câmara dos Deputados, 1992, p.6626).

Há pontos de aproximação e afastamento entre as polêmicas criadas por Bolsonaro e as polêmicas trazidas pelos grupos de pressão política de vocação ideológica. Como fatores de aproximação, o corporativismo, a defesa de uma solução militar ${ }^{3}$ e a descrença pelo poder civil. Mas, em torno de pautas, há significativas diferenças em forma e conteúdo. Em seus discursos, Bolsonaro acusa diretamente chefes militares a fim de chamar a atenção para a questão salarial. Já os manifestos dos grupos de pressão política não atacam as autoridades militares, limitam-se às autoridades civis.

Ao folhearmos as páginas do jornal Ombro a Ombro, notamos a pouca influência que Bolsonaro tinha, pelo menos até o ano de 1992, entre os grupos de pressão política de vocação ideológica. No âmbito das Forças, ele era proibido de entrar nos quartéis, e sequer fez parte da comissão de parlamentares que visitaria o Estado-Maior em 1992 para discutir a questão salarial.

Embora a questão salarial promovesse a candidatura de Bolsonaro e o aproximasse das praças e daquilo que podemos chamar de família militar, entre os grupos de pressão política havia quase que implícito um recorte hierárquico que o alienava. Interpretamos esse relativo distanciamento entre Bolsonaro e os grupos de pressão política em seus primeiros anos de carreira por vários fatores: 1) o primeiro, sem dúvida, é o caráter hierárquico uma vez que estes grupos eram dirigidos por generais e coronéis da reserva. 2) o segundo fator é profissional e corporativo Bolsonaro não fez parte da comunidade de informações e inteligência, o que poderia ser um fator de aproximação; 3) o terceiro fator era a própria estratégia de confronto adotada por Bolsonaro em suas prédicas no Congresso; 4) os objetivos políticos dos grupos de pressão não encontravam em Bolsonaro um articulador confiável.

\section{A aproximação - busca pela criação de uma bancada militar}

Porém, ao longo do governo Itamar será ensaiada uma aproximação. Esta aproximação deve ser compreendida à luz da crise do impeachment do presidente Fernando Collor. Cabe destacar que a ascensão e a queda de Fernando Collor de Mello haviam mobilizado os militares da reserva em

\footnotetext{
${ }^{3}$ Para se ter uma ideia, um grupo de pressão chamado Movimento de Salvação Nacional (MSN) começou a enviar panfletos nos quais incitavam a um golpe de Estado, prometendo "fuzilar a quadrilha tecnocrata comunista que serve à Presidência da República” (Pedrosa, 1991, p.5). A promessa era uma resposta ao veto feito em junho de 1991 pelo Congresso que derrubou a Medida Provisória (296) que garantia o reajuste dos militares. O MSN não foi o único grupo a usar da verborragia golpista.
} 
uma série de grupos de pressão política. Na literatura da transição, as medidas efetuadas no governo Collor apontam uma mudança nas relações entre civis e militares, em comparação ao governo Sarney (Oliveira, 1998; Castro e D'Araujo, 2001), em que pesem as críticas que vemos em Zaverucha (1994 e 2000). Seja pelo seu estilo pessoal, pela legitimidade dos votos da primeira eleição direta, pela escolha de ministros militares mais discretos e por algumas medidas efetuadas logo de sua posse, seja por seu processo de impeachment, no qual não houve interferência direta das Forças Armadas.

Na era Collor, há uma diminuição da influência dos militares nas estruturas governamentais já nos primeiros dias, com a extinção do Serviço Nacional de Informação (SNI), o rebaixamento de status do EMFA, entre outras medidas. Com o fim do SNI, alguns oficiais que faziam parte da comunidade de informações se aglutinam em um novo grupo de pressão política. Com sede em Fortaleza e dirigido pelo general da reserva Francisco Batista Torres de Mello, o grupo Guararapes será um dos mais expressivos ao longo da década de 1990. Entre seus integrantes, teremos o general Luciano Salgado Campos, que foi chefe do SNI em Brasília no governo Costa e Silva, e o general Euclydes Figueiredo, irmão do ex-presidente Figueiredo e ex-comandante da ESG. Alguns dos discursos do grupo chegaram até a grande imprensa. Em vários momentos, a Secretaria de Assuntos Estratégicos da Presidência da República, que substituiu o SNI, fez dossiês sobre o Grupo Guararapes e sobre os demais grupos atuantes. No dossiê confidencial 025993/92 da SAE, há uma reprodução do documento "objetivos de luta", de 4 de fevereiro de 1992. Entre as metas definidas pelo grupo está manter as Forças Armadas orgulhosas de seu papel histórico como Poder Moderador da Nação. Além disso, as Forças Armadas deveriam ser democráticas de acordo com sua tradição. A ideia do Poder Moderador e de democracia tutelada é uma constante nos demais grupos.

A crise que resulta no impeachment de Collor produz dois comportamentos. Na cúpula das Forças Armadas, o gradativo abandono do presidente e a escolha pela solução de acordo com o previsto na lei do Impeachment e na Constituição Federal, sem atuação das Forças Armadas, resulta em algo inédito nas relações civis e militares brasileiras. A ausência do ator militar, embora tenha sido saudada como amadurecimento da democracia por civis, não era vista com unanimidade entre os militares da reserva. Os setores mais radicais buscavam o intervencionismo militar. Além do Grupo Guararapes, mais quatro grupos surgem a reboque da crise do governo Collor e se somam aos demais: o Conselho de Mobilização Nacional, o Farroupilha (RS), o Inconfidência (MG), o Araucária (PR). A estratégia de pressão destes grupos reside no envio de manifestos à grande imprensa e a políticos. Os manifestos alternam entre a exortação direta ao golpe e o chamamento mais discreto às forças políticas. Essa dualidade, proposital, para fazer pressão, é chamada pelo general Newton Cruz de linha macarrão: “ora mole, ora dura” (Conti, 1994 apud Santos, 2009, p.102). 
Mesmo com a renúncia de Fernando Collor, no final de 1992, mais grupos são criados com a crise no Congresso devido ao escândalo dos anões do orçamento, e surgem mais manifestos a favor de ações manu militari. São eles: o Potiguar (RN), Cabanos (PA) e Bandeiras (SP). A crise do impeachment também amplia o anseio dos integrantes destes grupos em constituir uma bancada militar e nota-se uma aproximação entre estes grupos e militares que haviam abandonado os quartéis para seguir carreira parlamentar, como Bolsonaro. Em 1993, o jornal Ombro a Ombro empreende uma campanha por mobilização dos militares em prol de eleger deputados nas eleições do ano seguinte.

Em junho de 1993, Bolsonaro havia defendido o fechamento do Congresso Nacional e organizado uma manifestação com esposas de militares no qual defendia o retorno da ditadura. A repercussão lhe rendeu uma ação penal pública e a reação positiva dos grupos de pressão política da extrema-direita. Em julho de 1993, militares pertencentes aos grupos Araucária (Paraná) e Guararapes (Ceará), enviaram uma carta ao Corregedor do Congresso Nacional, deputado Vital do Rego, ameaçando-o de morte caso fosse levado o processo de cassação do deputado Jair Bolsonaro (Santos, 2009, p.95). Em agosto de 1993, Bolsonaro participa de um encontro no Clube Militar com a presença de 11 grupos de pressão política. Neste encontro, são discutidas as propostas para candidaturas de militares para o Congresso. A descrença destes militares sobre a política é reproduzida em uma pequena nota do Jornal do Brasil, de 21 de agosto de 1993. Entre os pontos que chamam a atenção, está a defesa, por parte de Bolsonaro, de um sistema de urnas eletrônicas, que seria mais fiável que o de papel. ${ }^{4}$ Afirma ele, que "esse Congresso está mais do que podre. Estamos votando uma lei eleitoral que não muda nada. Não querem informatizar as apurações pelo TRE. Sabe o que vai acontecer? Os militares terão 30 mil votos e só serão computados 3 mil" (Sholl, 1993, p.4).

As edições de Ombro a Ombro recebem anúncios de várias candidaturas para as eleições de 1994. A campanha impulsionada pelos grupos de militares da reserva não obteve êxito, o que ressalta a diferença entre um grupo de pressão política e um partido político. No entanto, é visível na cultura desses militares a necessidade de algum canal de participação política, seja pela desconfiança em relação aos partidos hegemônicos, seja pelo próprio fato de que naquele momento, os militares representavam o passado não democrático e por isso, rendiam poucos votos. Dentro de um quadro de pouca cultura democrática, para os mais moderados, bastava a representação parlamentar; aos mais exacerbados, a intervenção militar.

A partir de 1994, o Clube Militar funcionará como uma espécie de lócus dos grupos de pressão política. Naquele ano, o general Hélio Ibiapina cria o grupo Estácio de Sá para promover sua candidatura ao Clube Militar, com vista às eleições internas de 1996. Com a vitória, o Clube

\footnotetext{
${ }^{4}$ Como presidente, Bolsonaro lançou campanha contra as urnas eletrônicas, alegando possibilidade de fraude.
} 
Militar se tornará promotor da memória do regime militar e ponto de apoio dos militares que poderiam ser processados pelo governo. É de sua iniciativa, apoiada pelo então ministro do Exército Zenildo Zoroastro de Lucena, a mudança do perfil da revista do Clube, que passará a promover artigos sobre a memória de 1964 (Santos, 2009, p.70).

Durante o mandato de Fernando Henrique Cardoso e a implantação de uma política pública voltada aos Direitos Humanos, há uma nova onda de grupos que vão questionar as indenizações dadas às vítimas de violações de direitos na ditadura e a revelação de implicados em crimes de lesahumanidade. Entre os marcos dessa política, destaca-se a criação da Comissão de Mortos e Desaparecidos. Como resposta a essa política, serão criados os grupos Catarina (SC), Terrorismo Nunca Mais (RJ e DF) e Quero-quero (RS); e o Clube Militar, sob administração do general Ibiapina, terá importante papel na disseminação de uma memória positiva sobre o regime militar.

A memória de 31 de março de 1964, então presente nos manifestos dos grupos publicados no Letras em Marcha e em Ombro a Ombro, será reverenciada em atividades no Clube Militar, em sua revista, em cerimônias na sede do Comando Militar do Leste, e farão parte de uma disputa política em um momento em que o governo tem a possibilidade de efetivar uma política de Defesa Nacional e uma política de Direitos Humanos conjugados com uma aspiração democrática e vinculada a um controle civil dos militares. A reação destes militares continua com a criação do grupo Terrorismo Nunca Mais (Ternuma), sediado no Clube Militar, no Rio de Janeiro e com uma sucursal na capital federal. O Ternuma, por meio de seu site, será o lado visível dos militares da reserva ligados à comunidade de informações e segurança. Por sua vez, o ministério do Exército, em um de seus últimos atos administrativos, aprovará a coleção de História Oral do Exército, que reforça a narrativa de alguns atores a respeito daquele período histórico.

É neste período que haverá uma aproximação dos discursos de Bolsonaro na Câmara dos Deputados com a prédica destes grupos de pressão política. Essa aproximação pode ser vista já no final do governo Itamar Franco, quando Bolsonaro discursa, pela primeira vez na Câmara dos Deputados, defendendo a "revolução" de 1964, reproduzindo uma carta de autoria do coronel da reserva Ney Salles. Em que pese ser um deputado conhecido mais pelas declarações polêmicas à imprensa, incluindo a defesa de golpe, até então ele havia discursado 194 vezes no plenário e nunca tinha assumido clara e oficialmente a defesa do regime militar. Nos anos seguintes, veremos a defesa do regime de 1964 dentro de um campo maior de reação dos militares à política de Direitos Humanos implementada no governo FHC.

Em março de 1996, Bolsonaro discursa ao plenário, afirmando que "a tentativa de reabrir casos de terrorismo do passado, lançando culpa nos militares, parece ser a ordem do dia dos irresponsáveis de sempre" (Câmara dos Deputados, 1996-a, p.07196). Em junho de 1996, ele faz um discurso defendendo a memória do soldado Mario Kozel, morto pelos militantes da Vanguarda 
Popular Revolucionária (Câmara dos Deputados, 1996-b, p.18324). Neste mês, ele anuncia criar um projeto para indenização dos parentes de militares mortos pelas organizações da esquerda armada (Câmara dos Deputados, 1996-c, p.16240). Para Godoy, a atuação do tenente-coronel João Noronha Neto, agente do Centro de Informações do Exército, teria sido determinante para a reaproximação entre Bolsonaro e o Exército, "uma aproximação que se fazia sem que as mentalidades da Força ou de Bolsonaro tivessem mudado" (2021, p.55). Essa aproximação foi, contudo, gradual. A defesa da memória do regime militar é um dos temas marcantes do bolsonarismo.

O aspecto geracional foi um fator que distanciou Bolsonaro destes militares da reserva e que acabaria, anos mais tarde, aproximando-o dos novos chefes do Exército. A partir da década de 2000, Bolsonaro passa a ser distinguido com condecorações e medalhas militares nas três Forças - é neste período que os oficiais que entraram na academia militar na década de 1970 passam a integrar a alta cúpula (Santos, 2021). Em 2010, um pouco antes de sua campanha, que tem início em 2014, veremos um novo ativismo, associado a militares que desejam se organizar em um partido (Santos,2015). Embora novas pesquisas devam ser feitas para melhor explicar esse fenômeno, a demanda por representação política dialoga com o ativismo dos grupos de pressão política de viés ideológico e com as associações de militares que se constituíram entre as décadas de 1980 e 1990. Cabe lembrar que o Clube Militar, entidade que se tornou um reduto discurso pró-regime militar desde 1996, acabou se tornando a plataforma para a carreira política do general Antonio Hamilton Mourão, vice de Bolsonaro.

\section{Conclusão}

A participação dos militares da reserva na política no Brasil a partir da redemocratização origina-se de uma percepção sobre a redução de seu papel estamental e político. Diante da possibilidade da perda de status e poder, alguns militares se organizarão em grupos de pressão política. As gerações de oficiais que constituíam os grupos de pressão política estavam ligadas a um perfil de participação política dos militares vigente entre as décadas de 1930 e 1980 - período no qual os militares intervieram na política, com apoio laudatório da sociedade. A redemocratização e suas demandas, incluindo aí a revisão da lei de Anistia e o julgamento dos militares, permitiram um relativo isolamento político das Forças Armadas do jogo político-partidário. $\mathrm{O}$ ativismo dos grupos aqui analisados é um sintoma e uma resposta a esse isolamento.

Não devemos pensar que Bolsonaro e estes grupos de pressão política de militares da reserva são representantes de uma suposta homogeneidade do Exército. Há distintas correntes dentro da instituição, ora visíveis, ora invisíveis. Ao longo da década de 1990, as diferentes composições políticas permitiam ainda um leque de aproximações, alianças que poderiam se efetivadas em torno de uma pauta específica e serem rapidamente desfeitas dentro do jogo político. Embora não haja 
homogeneidade, mostramos ao longo do artigo que a mobilização dos militares, da ativa e da reserva, em torno dos ideais anticomunistas não é um fenômeno recente.

Embora este trabalho tenha dado especial atenção aos grupos de pressão política e tenha buscado mostrar aproximações e afastamentos destes com os discursos e ações de Bolsonaro como parlamentar, ainda há novas investigações que podem ser feitas sobre o papel das associações militares e dos parlamentares de origem militar eleitos no período, assim como com as organizações civis. No entanto, mesmo com as limitações de espaço e tempo de um artigo científico exploratório, pretendemos contribuir para este primeiro debate.

Duas décadas depois do início da transição, a maior parte dos grupos de pressão política formados por militares da reserva deixava de existir devido a não renovação de seus quadros. A extrema-direita no meio militar era um problema mais de caráter institucional do que um problema político. Porém, parte de seus discursos, sua cosmovisão, bem como as prédicas da Comunidade de Informações ao qual alguns de seus integrantes fizeram parte, serão reproduzidos no avanço da extrema-direita liderada por Bolsonaro. Imerso no anticomunismo, no ressentimento e na desconfiança sobre a política civil, os discursos que elegem Bolsonaro repetem a ideologia da extrema-direita militar dos anos 80 e 90.

Se este é o retorno definitivo dos militares à política no Brasil, ou apenas seu último e longo suspiro, a resposta caberá ao sistema político-partidário, suas instituições e a sua capacidade de mobilizar e persuadir a sociedade, integrar as demandas dos militares e legitimar o seu poder. Em uma democracia, o problema militar é um problema eminentemente civil, e a solução aos extremos é a moderação.

\section{Referências}

Aragão, M. (1994) Grupos de pressão no Congresso Nacional - Como a sociedade pode defender licitamente seus direitos no poder legislativo, $1^{\mathfrak{a}}$ ed., São Paulo: Maltese.

Agência Central do SNI (1985), Arquivo Cronológico de Entrada (ACE) no 047091/85, de 04 de janeiro. . (1988-a) Arquivo Cronológico de Entrada no066409/88, de 21 de junho. . (1988-b) Arquivo Cronológico de Entrada no067428/88, 08 de setembro. . (1989) Arquivo Cronológico de Entrada no072519/89, 25 de outubro.

Agência Regional do SNI (1989), Arquivo Cronológico de Entrada (ACE) no 8645, de 12 de junho.

Bobbio, Norberto, Matteucci, Nicola, Pasquino, Gianfranco. (2004) Dicionário de Política, 12ª ed., Brasília: Ed. UnB, v. 1 e 2.

Bartle, R. Heinecken, L. (2006) Military Unionism in The Post-Cold War Era: A Future Reality? (Cass Military Studies), Kindle Edition, Taylor and Francis.

Castro, C. e D’Araújo, M.C (2000) - Democracia e Forças Armadas no Cone Sul. 1ª ed., Rio de Janeiro: Ed FGV. 
Santos, Eduardo Heleno de Jesus. Ativismo e extrema-direita no meio militar: tensões e discursos que antecedem o bolsonarismo (1984-1998).

. Militares e política na Nova República (2001), $1^{\text {a }}$ ed, Rio de Janeiro: Ed FGV.

Castro. C. (2021) General Villas Bôas: Conversa com o Comandante, Kindle Edition, Rio de Janeiro: Ed.FGV.

CIE (1989-a), Centro de Informações do Exército, Relatório Periódico Mensal, no5.

CIE (1989-b), Centro de Informações do Exército, Relatório Periódico Mensal, no9.

Chirio, M (2012). A política nos quartéis. Revoltas e protestos de oficiais na ditadura militar brasileira. Rio de Janeiro: Zahar.

Conti, Luciana (1994). Guararapes, o golpe que não houve. Jornal do Brasil, 27 de março, p.6.

Câmara dos Deputados (1991-a). Diário da Câmara dos Deputados, Brasília, 23 de abril.

. (1991-b). Diário da Câmara dos Deputados, Brasília, 24 de setembro.

. (1992). Diário da Câmara dos Deputados, Brasília, 10 de abril.

. (1996-a). Diário da Câmara dos Deputados, Brasília, 20 de março.

(1996-b) Diário da Câmara dos Deputados, Brasília, 5 de junho.

(1996-c) Diário da Câmara dos Deputados, Brasília, 6 de junho.

Dreifuss, R. A (1989). O jogo da direita, $3^{\text {a }}$ ed., Rio de Janeiro: Vozes.

Filho, Expedito; Tognozzi, Marcelo; Dias, Etevaldo (1987), “Linha-dura do Exército se une para fazer política”. Jornal do Brasil, Rio de Janeiro, 18 de outubro, p.8.

Godoy, M. (2021-a). Soldados influenciadores: os guerreiros digitais do Bolsonarismo e os tuítes de Villas Boas, In: Martins Filho (org). Os militares e a crise política, São Paulo, Alameda.

. (2021-b) Para 'guru', Bolsonaro fazia 'jogo' da esquerda, Estadão, 24 de fevereiro de 2019, disponível em https://politica.estadao.com.br/noticias/geral,para-guru-bolsonaro-fazia-jogo-da-esquerda,70002733749,

acesso em 29 de agosto de 2021.

Jornal do Brasil (1984), 22 de julho, Caderno B, p.3.

Kubik, E. (2019) Superior Tribunal Militar: mudança institucional, ideias e atores na ditadura militar (1964/1979), tese defendida no PPGCP-UFF.

Lopez, E. (2001) Objective and Subjective Control Revisited. In: PION-BERLIN, D. (Org). Civil Military Relations in Latin-America: New Analytical Perspectives. North Carolina Press.

Martins Filho, J.R (2008). A influência doutrinária francesa sobre os militares brasileiros nos anos de 1960. Revista Brasileira de Ciências Sociais - Vol. 23, № 67.

Meynaud, J.(1966) Os grupos de pressão. Trad. de Pedro Lopes de Azevedo. Coleção Saber. Lisboa: Publicações Europa-América.

Pedrosa, F. Queda da MP aumenta a insatisfação nos quartéis. Jornal do Brasil, Rio de Janeiro, 30 de junho de 1991, p.5.

Santos, E.H.J (2009) Extrema-direita volver! Os grupos formados por civis e militares da reserva. Dissertação de Mestrado, PPGCP-UFF.

. (2012) Das trincheiras à guerra de atrito: a batalha pela memória entre os militantes da esquerda e os militares da reserva de extrema-direita deixou, enfim, de ser silenciosa? Trabalho apresentado no GT 23 - Forças Armadas e 
Santos, Eduardo Heleno de Jesus. Ativismo e extrema-direita no meio militar: tensões e discursos que antecedem o bolsonarismo (1984-1998).

Sociedade. In: 36ํㅜ Encontro da Associação Nacional de Pesquisa e Pós-Graduação em Ciências Sociais Anpocs.

\section{PPGCP-UFF.}

. (2015) Grupos de Pressão Política Formados por Militares da Reserva no Mercosul, tese de doutorado,

(2018) Forças Armadas, Militares da Reserva, Anticomunismo e a Comissão Nacional da Verdade -

Memórias em Disputa In: Aguilar, S. (org) Os desafios da política externa e segurança no século XXI Marília: Oficina Universitária; São Paulo: Cultura Acadêmica.

. (2021) Controle Civil? A ascensão de Bolsonaro e a encruzilhada no Brasil - militares, forças armadas e política. In: Martins Filho (org). Os militares e a crise política, São Paulo, Alameda.

Santos, E.H.J., Alves, V. C., Figueiredo, E. L. (2008) O velho e o novo no discurso das Forças Armadas. Trabalho apresentado no GT 32 - Forças Armadas e Sociedade. In: 32ํㅡㄹ Encontro da Associação Nacional de Pesquisa e Pós-Graduação em Ciências Sociais - Anpocs.

Soares, S. A (2006). Controle e autonomia. As Forças Armadas e o sistema político brasileiro (1974-1999). São Paulo: Ed.Unesp.

Sholl, D. Agitação na reserva. Jornal do Brasil, Rio de Janeiro, 21 de agosto de 1993, p.4.

Stepan, A (1975). Os militares na política. As mudanças de padrões na vida brasileira. Trad. de Ítalo Tronca. $1^{\text {a }}$ ed., Rio de Janeiro: Artenova.

Zaverucha, J. (1994) Rumor de Sabres, 1ํㅗㄹ., São Paulo: Ed. Ática. . (2000) Frágil democracia. $1^{a}$ ed. Rio de Janeiro: Civilização Brasileira. 